\title{
A Catalogue of Non-Technical Requirement Patterns
}

\author{
Cristina Palomares, Carme Quer, Xavier Franch \\ Universitat Politècnica de Catalunya \\ Barcelona, Catalunya, Spain \\ \{cpalomares, cquer,franch\}@essi.upc.edu
}

\author{
Cindy Guerlain, Samuel Renault \\ Public Research Centre Henri Tudor \\ Luxembourg, Luxembourg \\ \{samuel.renault, cindy.guerlain\}@tudor.lu
}

\begin{abstract}
Software Requirement Patterns (SRP) have been proposed as an artifact for fostering requirements reuse. PABRE is a framework that promotes the use of SRP as a means for requirements elicitation, validation and documentation in the context of IT procurement projects. In this paper, we present a catalogue of non-technical SRP included in the framework and present in detail some of them. We also introduce the motivation to arrive to these patterns.
\end{abstract}

Keywords-software requirement patterns; requirements reuse

\section{MOTIVATION}

The work presented in this paper stems from the needs of the Public Research Centre Henri Tudor (TUDOR) at Luxembourg when conducting IT procurement projects over time. Since 2004, TUDOR works in collaboration with freelance and independent consultants. These consultants are federated in a business network that we refer as CASSIS. They are trained to innovative methods produced by research projects and they use these methods in industrial contexts. TUDOR monitors the application of these methods by consultants to ensure that they do not deviate over time.

One of the main methods delivered to consultants is a requirement engineering method used to design Software Requirements Specification documents (SRS) for IT procurement projects in small and medium size companies [1]. Consultants work in collaboration with customers to help them in identifying their needs for a new IT system supporting their business activities, and then selecting the most relevant system accordingly to their needs. In this particular context, requirements engineers' consultants define SRS for external customers and not for their internal purpose. Consultants' customers are usually looking both for an IT system and for its implementation. In other words, they have requirements towards an IT system and towards additional services. For this reason, the scope of the SRS often encompasses functional (F), non-functional (NF) [2] and non-technical (NT) [3] requirements. According to the empirical feedback of Tudor experimentation with public and private organisations, when selecting a business software solution, usually an organisation needs to address the three kinds of requirements. We have observed that $\mathrm{F}$ requirements are the most important in number and criticality, whilst NF and NT requirements are the most redundant or similar in between projects.
So far, consultants and TUDOR have performed more than 40 projects in compliance with that method. The initial approach for capitalising requirements knowledge among the consultants was quite basic. It consisted in reusing fragments of a former SRS as a basis to build the new SRS. This approach was simple to use but required to be aware of the former projects, which was not easy for the consultants due to their decentralized organisation in a business network.

The second TUDOR approach to capitalise requirements knowledge was to design SRS' templates based on existing SRS with similarities. This approach no longer requires the consultants to be aware of all former projects. However, the SRS' templates remained unstructured as domain experts built them both on their own knowledge and on assumptions of similarities found in existing SRS but without any underlying metamodel.

The limitations of these reuse approaches led TUDOR to collaborate with the Software Engineering for Information Systems research group (GESSI) at the UPC to define new artefacts, methods and techniques for requirements reuse. Specifically the PABRE framework [4] that arose from this collaboration is based in the use of Software Requirement Patterns (SRP) as those presented in this paper.

In Section II we show the main parts of the structure of the PABRE SRP by means of an example. Next, in Section III we present the overall structure of an NT SRP catalogue. The main part of the paper is Section IV where we introduce two examples of SRP following the workshop pattern template to structure them. Finally, some conclusions are given in Section V. It is not the aim of this paper to explain neither the SRP metamodel, nor the process for obtaining or method for using the catalogue in requirements elicitation processes, we refer to [4][5][6] for details in these aspects.

\section{PABRE SRP STRUCTURE}

We present the structure of PABRE patterns through an example, the Economic Situation pattern (see Fig. 1), that illustrates the structure of patterns and helps to understand the metamodel behind them [5].

An SRP is a pattern that, when applied, produces software requirements related to the objective (goal) of that pattern. Applying the Economic Situation SRP we may produce requirements related to the goal of Assessing the economic situation of the supplier that procures a software system, as could be the supplier company's turnover or net incomes. 


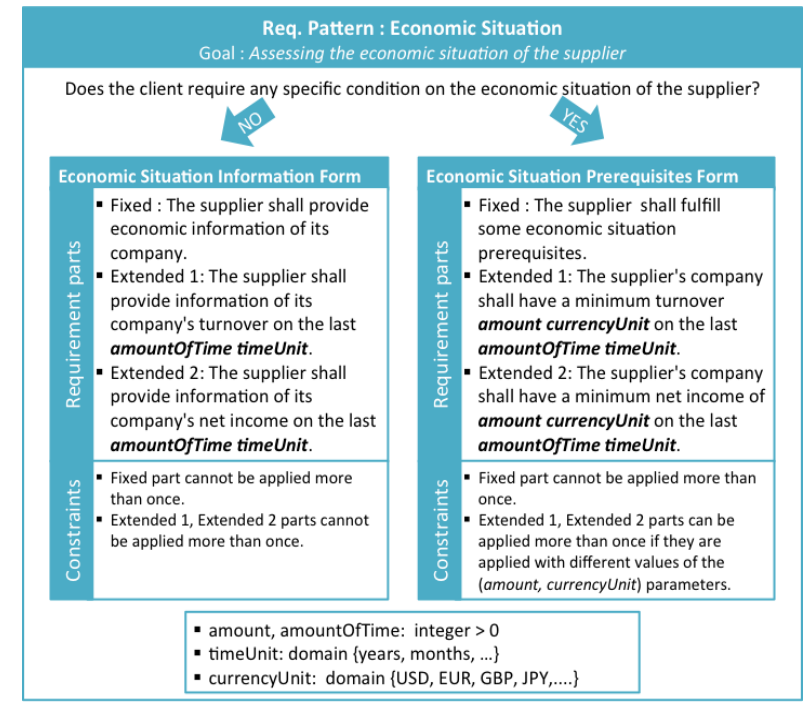

Figure 1. Economic Situation Pattern

A goal can be achieved in different ways. An SRP consists of several Forms, each one representing a different solution for achieving the goal. In the Economic Situation SRP, its goal can be attained by asking the supplier the relevant economic information (Economic Situation Information form), or by setting conditions or prerequisites on the economic situation that the supplier should have (Economic Situation Prerequisites form).

We organize Forms into Parts, each of them being a template. Each Form is characterized by a Fixed Part which states the minimal requirement that always holds when applying that form, and some Extended Parts which may be applied or not. The Fixed Part always becomes a requirement when an SRP is applied with this Form. Extended Parts are only used if more precise information is required in the specification. Due to this nature, the Fixed Part is usually quite generic and hardly measurable. For instance, the first form of Economic Situation is The supplier shall provide economic information of its company, whilst the two extended parts identify the type of information required (company's turnover or net income) and the period of time.

Usually, fixed and extended parts must conform to some Part Constraint represented by means of a regular expression that may involve some predefined operators (e.g., for declaring multiplicities or dependencies among parts, as Excludes and Requires). In the Economic Situation SRP, each part of the forms may be used just once in a specification project, and neither excludes nor requires dependencies among them.

From a syntactic point of view, both fixed and extended parts are similar. They are composed by the text to be used as a requirement and optionally some parameters to be instantiated when applying the pattern. Parameters establish their Metric, eventually a correctness condition inv, and also may be related to other parameters (belonging to other patterns) such that they must have the same value. The second form in the Economic Situation SRP declares two extended parts that identify additional conditions on this form. For example, the second extended part allows stating prerequisites on the net supplier incomes (by assigning values to the parameters amount and currencyUnit, e.g. $1 \mathrm{M}$ EUR) for a certain period of time (by assigning values to the parameters amountOfTime and timeUnit, e.g. 2 years). The metrics and the correctness conditions of the parameters are detailed at the bottom of the figure.

\section{THE NT SRP CATALOGUE}

The NT SRP were obtained after mining 6 SRS from past projects conducted by TUDOR and the consultants. They are a part of a bigger catalogue, which currently contains other $29 \mathrm{NF}$ patterns and $47 \mathrm{~F}$ patterns that apply on the Document Management Systems domain.

The SRP are organized and classified in the catalogue by means of one or more schemas, and give different views to the consultants for facilitating its browsing during requirements elicitation. The idea is to provide to different people with different background a different view of the catalogue with which they are used (see Fig. 2). For instance, TUDOR, and its trained consultants, have their own requirements classification, whilst the GESSI team usually works with the ISO/IEC 9126-1 standard [7].

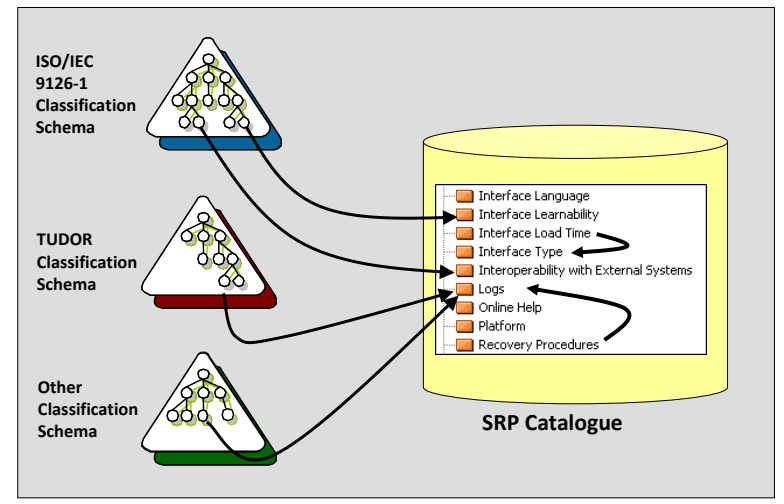

Figure 2. SRP Catalogue Classification Schemas

In this paper we organize the catalogue using an ISO 9126-based schema. However, since in this standard the characteristics and subcharacteristics do not address nontechnical aspects of software, we used the NT-ISO/IEC 9126 catalogue that we proposed in previous works [3]. This extension adds 3 characteristics (Supplier, Business and Product) and 15 subcharacteristics to the standard. Before classifying the NT SRP according to this schema, some changes had to be done to take into account some differences on the use of the catalogue.

On the one hand, initially that catalogue was created to include the criteria to assess the quality of a final software product, whereas the NT SRP state requisites for the procurement of a system (probably by gluing or adapting several products). This is the reason why we needed to add a new characteristic to group the SRP about the 
implementation project: the Project characteristic, decomposed into two subcharacteristics: Business Scheduling and Supplier Relationships.

On the other hand, some related subcharacteristics were merged into just one. Specifically, they were those related to the cost of the business. The original subcharacterstics were too static: Licensing Costs, Platform Costs, Implement Costs and Network Costs, but the new subcharacteristic integrates all these costs in a cost breakdown structure allowing the flexibility to add new ones.

Table I shows the resulting classification. It is worth to mention that most of the subcharacteristics have some NT SRP bound which is an indicator that the projects used as baseline data were comprehensive enough.

TABLE I. NT SRP CLASSIFICATION ACCORDING TO NT-ISO/IEC 9126

\begin{tabular}{|c|c|}
\hline 1. Supplier & NTSRP \\
\hline \multirow{3}{*}{$\begin{array}{l}\text { 1.1 Organizational } \\
\text { Structure }\end{array}$} & - Supplier Administrative Information \\
\hline & - Supplier Organization \\
\hline & - Supplier History \\
\hline \multirow{2}{*}{$\begin{array}{l}\text { 1.2 Positioning and } \\
\text { Strength }\end{array}$} & - Supplier Economic Information \\
\hline & - Supplier Workforce \\
\hline \multirow{2}{*}{1.3 Reputation } & - Supplier Business Experience \\
\hline & - Supplier Quality Certification \\
\hline 1.4 Services Offered & - Training \\
\hline \multirow{2}{*}{ 1.5 Support } & - Maintenance Procedure \\
\hline & - Type of Maintenance \\
\hline \multicolumn{2}{|l|}{ 2. Product } \\
\hline \multirow{2}{*}{2.1 History } & - Product History \\
\hline & - Community Support \\
\hline \multirow{2}{*}{ 2.2 Deliverables } & - Delivered Documentation \\
\hline & - Source Code \\
\hline $\begin{array}{l}\text { 2.3 Parameterization and } \\
\text { Customization }\end{array}$ & \\
\hline \multicolumn{2}{|l|}{ 3. Business } \\
\hline 3.1 Licensing Schema & • $\quad$------------------ \\
\hline 3.2 Ownership & - Intellectual Property Rights \\
\hline 3.3 Guarantees & - Warranty \\
\hline 3.4 Costs & - Cost Breakdown Structure \\
\hline \multicolumn{2}{|l|}{ 4. Project } \\
\hline \multirow{9}{*}{ 3.8 Business Scheduling } & - System Implementation Scheduling \\
\hline & - Progress Control \\
\hline & - Project Management Method \\
\hline & - Final acceptance \\
\hline & - Release \\
\hline & - Analysis \\
\hline & - Data Migration \\
\hline & - Development \\
\hline & - Acceptance Tests \\
\hline \multirow{11}{*}{ 3.9 Supplier Relationships } & - Steering Committee \\
\hline & - Meetings Organization \\
\hline & - Access to Customer Premises \\
\hline & - Privacy \\
\hline & - Progress Control \\
\hline & - Quality Assessment \\
\hline & - Payment Procedure \\
\hline & - Settlement of Disputes \\
\hline & - Supplier People Assigned to the Project \\
\hline & - Help Desk \\
\hline & - Crash Response \\
\hline
\end{tabular}

\section{THE NT SRP CATALOGUE}

We present here two of the NT SRP of our catalogue: Intellectual Property Rights (Tables II and III) and Quality Assessment (Tables IV and V). Tables II and IV show the SRP general attributes using the RePa workshop template. Tables III and V describe the SRP detailed solution according to the model presented in Section II.

The Intellectual Property Rights SRP (Table II) is suitable in procurement projects (RE Activity) where the customer wants to state the property right over of different deliverables obtained as a result of the system implementation project (Problem, which in our framework is named goal). The Forces in the customer organization influence in the Application of the SRP Solution, specifically in choosing which Parts and Parameter values to use.

TABLE II. “INTELLECTUAL PROPERTy Rights” PATTERN SUMMARY

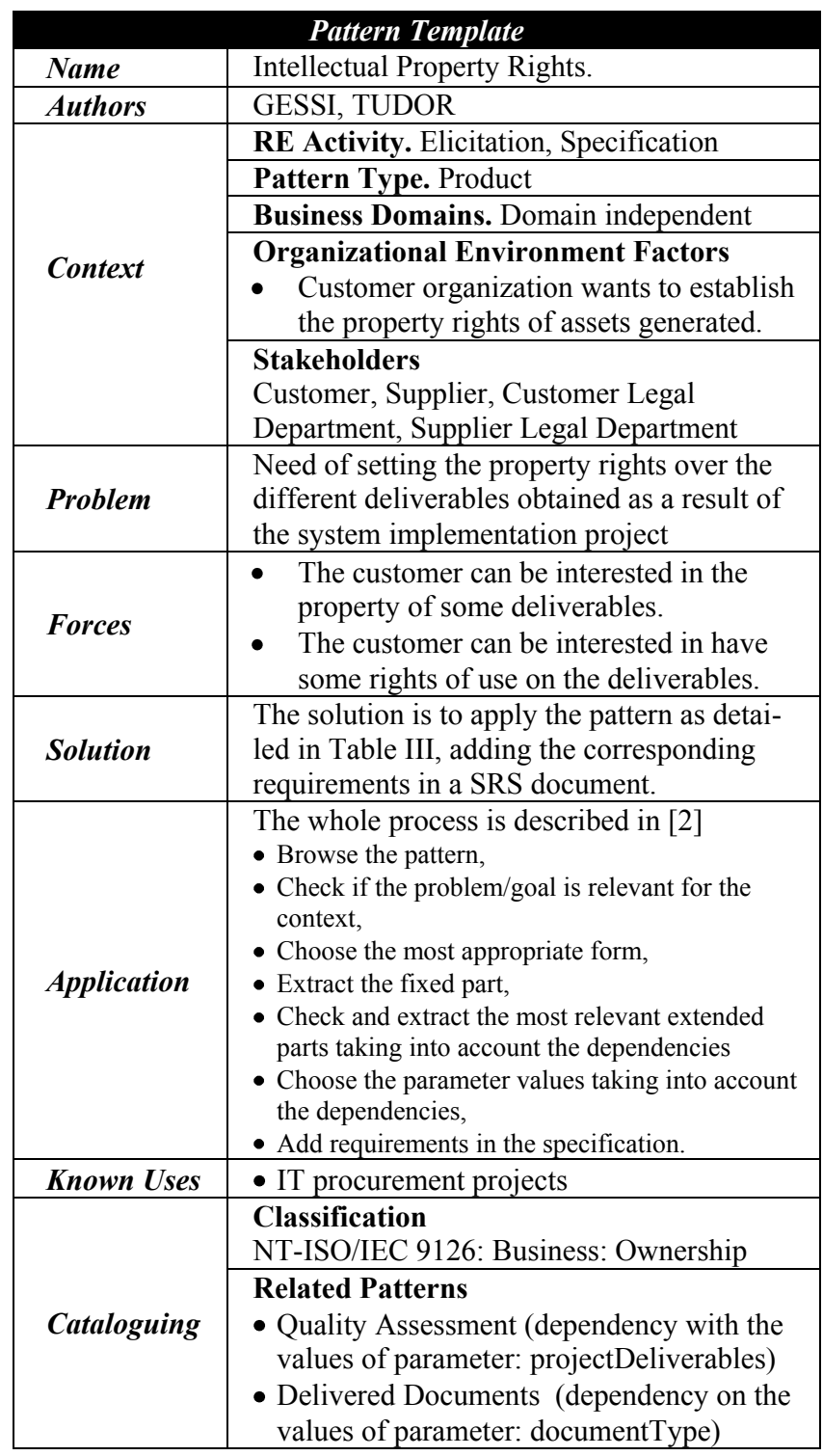




\begin{tabular}{|c|c|c|c|}
\hline \multicolumn{4}{|c|}{$\begin{array}{l}\text { Intellectual Property Rights } \\
\text { em implementation project }\end{array}$} \\
\hline \multirow{2}{*}{\multicolumn{4}{|c|}{$\begin{array}{l}\text { Description: This pattern expresses the need of setting the property rights over the different deliverables result of the system implementation project } \\
\text { Keywords: Project Deliverable, Project Asset, Intellectual Property, Property Rights }\end{array}$}} \\
\hline & & & \\
\hline \multirow{14}{*}{$\begin{array}{l}\text { Requirement } \\
\text { Form } \\
\text { Intellectual } \\
\text { Property Rights }\end{array}$} & Description & $\begin{array}{l}\text { This form expresses the need of setting the } \\
\text { system implementation project }\end{array}$ & operty rights over the different deliverables obtained as a result of the \\
\hline & Constraints & $\begin{array}{l}\text { Fixed part application: }\left(1 . .^{*}\right) \\
\text { Extended parts application: Project Del } \\
\text { Parameter values constraints: actor, pro }\end{array}$ & $\begin{array}{l}\text { erable Use (*); Project Assets Return (0..1) } \\
\text { ctDeliverables DisjointValues (Fixed Part, Project Deliverable Use) }\end{array}$ \\
\hline & \multirow{4}{*}{ Fixed Part } & Form Text & $\begin{array}{l}\text { At the end of the system implementation project, } \\
\text { projectDeliverables shall become property of the actor. }\end{array}$ \\
\hline & & Param & Metric \\
\hline & & $\begin{array}{l}\text { projectDeliverables is a non-empty set of } \\
\text { the different assets related to a system } \\
\text { implementation project (e.g., hardware, } \\
\text { software, documents, data, etc.) }\end{array}$ & $\begin{array}{l}\text { ProjectDeliverables }=\text { Set(ProjectDeliverable) } \\
\text { ProjectDeliverable }=\text { Domain (hardware, software, data and } \\
\quad \text { documents paid by customer as project deliverables, etc.) }\end{array}$ \\
\hline & & $\begin{array}{l}\text { actor represents one of the possible roles } \\
\text { related to a system implementation project } \\
\text { (usually the customer or the supplier) }\end{array}$ & Actor $=$ Domain (supplier, customer, etc. $)$ \\
\hline & \multirow{5}{*}{$\begin{array}{l}\text { Extended Part } \\
\quad \text { Project } \\
\text { Deliverable Use }\end{array}$} & Form Text & $\begin{array}{l}\text { At the end of the system implementation project the actor can use } \\
\text { IPRConditions the projectDeliverables }\end{array}$ \\
\hline & & Param & Metric \\
\hline & & actor as above & Actor as above \\
\hline & & projectDeliverables as above & ProjectDeliverables as above \\
\hline & & $\begin{array}{l}\text { IPRConditions represents the intellectual } \\
\text { property rights over some project } \\
\text { deliverable for some actor }\end{array}$ & $\begin{array}{l}\text { IPRConditions = Set (IPRCondition) } \\
\text { IPRCondition = Domain (freely, with no restriction, with non- } \\
\text { commercial use, with respect of License contract, etc.) }\end{array}$ \\
\hline & \multirow[b]{3}{*}{$\begin{array}{l}\text { Extended Part } \\
\text { Project Assets } \\
\quad \text { Return }\end{array}$} & Form Text & $\begin{array}{l}\text { The supplier shall return the project Assets that the customer } \\
\text { provided him just for the system implementation. }\end{array}$ \\
\hline & & Param & Metric \\
\hline & & $\begin{array}{l}\text { projectAssets is a non-empty set of the } \\
\text { different assets related to a system } \\
\text { implementation project (e.g. customer } \\
\text { business process documents, customer } \\
\text { company business reports, etc.) }\end{array}$ & $\begin{array}{l}\text { ProjectAssets }=\text { Set(ProjectAsset) } \\
\text { ProjectAsset = String (e.g. customer business process documents, } \\
\text { customer company business reports, etc.) }\end{array}$ \\
\hline
\end{tabular}

In the detailed solution (Table III), the constraints of use declare that, when applying the pattern, the fixed part can be used several times in a project $\left(1 .{ }^{*}\right)$, provided that the values of the attributes actor and projectDeliverables are different in each use. Thus, different deliverables may be property of different actors.

The first extended part helps to state the rights on projectDeliverables that are not property of an actor. This part can also be used more than once $(*)$, where uses are constrained by the same rule, i.e. it is not possible to have the same combination of parameters' values in different uses of the fixed and first extended part. The semantic behind the rule is that it is not possible to be the owner of a deliverable and require rights on that deliverable.

The second extended part allows stating the return of the assets that the supplier borrowed from the customer after finishing the project.

An example of application of this SRP in an IT project:

- At the end of the system implementation project, the software developed, the delivered documents (except the installation manuals) and the drivers shall become property of the customer.

- At the end of the system implementation project, the hardware, the installation manuals and development software shall become property of the supplier.

- At the end of the system implementation project, the customer can use paying some quota the hardware and the installation manuals.

- At the end of the system implementation project, the supplier can use freely the delivered documents.

- The supplier shall return the customer business process documents and the documentation of the substituted software system that the customer provided him just for the system implementation.

The SRP related to Intellectual Property Rights are: Quality Assessment and Delivered Documents (see Related Patterns in Table II). Both relationships are dependencies on the values of the parameters of each pattern. The idea is that if a certain statement of ownership or rights of use is required on a project deliverable, maybe it is necessary to stand the level of quality that such deliverable shall have, and if the deliverable is a document it should be among the documents delivered in the project (Delivered Documents).

The Quality Assessment SRP (Table IV) is suitable in procurement projects where the customer wants to state its right of performing quality assessment of the supplier or of the project deliverables. The Forces influence in the 
Application of the SRP Solution: depending on whether the customer wishes to do the assessment by some specific quality criteria or based on some quality standard a different Form will be applied. In the second case, the second form Quality Standard-based Assessment shall be used.

In the detailed solution (Table V), the constraints of use state that in the application of the pattern the fixed part has to be used once (1), and all the extended parts can be or not applied (0..1), except the Deliverables Quality Assessment extended part that can be used several times $(*)$ for different sets of project deliverables (see the Parameter values constraints). One application of the SRP could be:

- If the customer considers it necessary, during the system implementation project, $\mathrm{s} / \mathrm{he}$ shall be allowed to assess the quality of the process or project deliverables taking into account a quality standard.

- The quality of the software design documentation shall be assessed taking into account the IEEE 1016 quality Standard.

- The quality of the requirements specification document shall be assessed taking into account the IEEE 830 quality Standard.

- The customer shall establish the subset quality standard criteria to be applied before December 2012.

The SRP related to the Quality Assessment SRP are (Table IV): Supplier Quality Certification, Intellectual Property Rights, Delivered Documents. The first relationship is a dependency with the SRP Supplier Quality Certification: if a customer is interested in the Quality Assessment SRP $\mathrm{s} /$ he will be also interested in the Supplier Quality Certification SRP. The other two are dependencies on the values of the parameters projectDeliverables and documentType of the SRP Intellectual Property Rights and Delivered Documents respectively.

\section{CONCLUSIONS}

In this paper we have presented the overall structure of a set of non-technical SRP integrated in the PABRE framework, that are part of the catalogue constituted by 113 SRP (functional, non-functional and non-technical). We have illustrated the details of NT SRP by showing in detail two particular patterns. Besides the catalogue, the PABRE framework is built upon a pattern application process [4], a metamodel [5] and tool support [8]. Currently, the catalogue is available under a specific Creative Commons license that allows its use in non-commercial way (e.g. for research and experimentation purpose) but without derivative works [6].

The value of the approach has been qualitatively identified as positive from first practitioners' feedback collected in a survey addressed to practitioners who produced the SRS documents on which we based to build the approach. We are currently setting-up the experiment with practitioners that will bring enough data for quantitative analysis of the value of the approach.
Our future work will consist on progressing with the validation and evolution of the NT SRP catalogue and the supporting tools. Also, we aim at adopting techniques to help in the detection of SRP in SRS documents.

TABLE IV. "QUALITY ASSESSMENT" PATTERN SUMMARY

\begin{tabular}{|c|c|}
\hline \multicolumn{2}{|r|}{ Pattern Template } \\
\hline Name & Quality Assessment. \\
\hline Authors & GESSI, TUDOR \\
\hline \multirow{5}{*}{ Context } & RE Activity. Elicitation, Specification \\
\hline & Pattern Type. Product \\
\hline & Business Domains. Domain independent \\
\hline & $\begin{array}{l}\text { Organizational Environment Factors } \\
\text { Customer organization that gives importance to the } \\
\text { quality assessment practices. }\end{array}$ \\
\hline & $\begin{array}{l}\text { Stakeholders } \\
\text { Customer, Supplier, Customer Quality } \\
\text { Department, Supplier Quality Department, } \\
\text { Supplier Project Management Office }\end{array}$ \\
\hline Problem & $\begin{array}{l}\text { Need of setting the customer right for performing } \\
\text { quality assessment of the supplier or the project } \\
\text { deliverables. }\end{array}$ \\
\hline Forces & $\begin{array}{l}\text { The customer can be interested or not in a certain } \\
\text { standard for assessing the quality of software. }\end{array}$ \\
\hline Solution & $\begin{array}{l}\text { The solution is to apply the pattern, as in Table V, } \\
\text { adding the corresponding requirements in an SRS. }\end{array}$ \\
\hline Application & $\begin{array}{l}\text { The whole process is described in [2] (see Table } \\
\text { III for more details) }\end{array}$ \\
\hline Known Uses & - IT procurement projects \\
\hline \multirow[b]{2}{*}{ Cataloguing } & $\begin{array}{l}\text { Classification } \\
\text { NT-ISO/IEC 9126: Project: Supplier relationships }\end{array}$ \\
\hline & $\begin{array}{l}\text { Related Patterns } \\
\text { - Supplier Quality Certification (the customer } \\
\text { that applies Quality Assessment can be also } \\
\text { interested in this pattern) } \\
\text { - Intellectual Property Rights (dependency with } \\
\text { the values of parameter: projectDeliverables) } \\
\text { - Delivered Documents (dependency on the } \\
\text { values of parameter: documentType) }\end{array}$ \\
\hline
\end{tabular}

\section{ACKNOWLEDGMENT}

This work has been partially supported by the Spanish project TIN-2010-19130-C02-01.

\section{REFERENCES}

[1] S. Renault, B. Barafort, E. Dubois, M. Krystkowiak. Improving SME Trust into IT Consultancy: a Network of Certified Consultants Case Study. EuroSPI 2007.

[2] K. Pohl. Requirements Engineering: Fundamentals, Principles, and Technique. Springer, 2010.

[3] J. P. Carvallo, X. Franch, C. Quer: Managing Non-Technical Requi-rements in COTS Components Selection. RE 2006.

[4] S. Renault, O. Mendez-Bonilla, X. Franch, C. Quer: A Pattern-based Method for building Requirements Documents in Call-for-tender Processes. IJCSA 6(5), 2009.

[5] C. Palomares, C. Quer, S. Renault, F. De Lazzer. A Metamodel for Software Requirement Patterns. REFSQ 2010.

[6] http://www.upc.edu/gessi/PABRE/

[7] ISO/IEC 9126-1-2001 Software Engineering Product Quality Part 1: Quality Model, International Standards Organization, 2001.

[8] C. Palomares, C. Quer, X. Franch. PABRE-Man: Management of a Requirement Patterns Catalogue. RE 2011. 
TABLE V. NT SRP "QuALITY ASSESSMENT": DETAILED SOLUTION

\begin{tabular}{|c|c|c|c|}
\hline \multicolumn{4}{|c|}{ 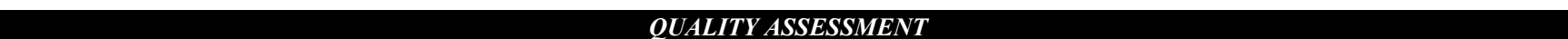 } \\
\hline \multirow{2}{*}{\multicolumn{4}{|c|}{$\begin{array}{l}\text { Description: This pattern expresses the need of setting the customer right for performing quality assessment of the supplier or of the project deliverables. } \\
\text { Keywords: Quality, Quality assessment, Quality criteria, Quality standard }\end{array}$}} \\
\hline & & & \\
\hline \multirow{9}{*}{$\begin{array}{l}\text { Requirement Form } \\
\text { General Quality } \\
\text { Assessment }\end{array}$} & Description & $\begin{array}{l}\text { This form expresses the need of setting } \\
\text { supplier or the project deliverables rege }\end{array}$ & $\begin{array}{l}\text { the customer right for performing quality assessment of the } \\
\text { Irding to specific customer quality criteria. }\end{array}$ \\
\hline & Constraints & $\begin{array}{l}\text { Fixed part application: }(1) \\
\text { Extended parts application: } \\
\quad \text { Review Focus }(0 . .1) \\
\text { Quality Criteria Agreement }(0 . .1)\end{array}$ & \\
\hline & \multirow[b]{3}{*}{ Fixed Part } & Form Text & $\begin{array}{l}\text { If the customer considers it necessary, during the system } \\
\text { implementation project, } \mathrm{s} / \text { he shall be allowed to assess the } \\
\text { quality of the process or the projectDeliverables. }\end{array}$ \\
\hline & & Param & Metric \\
\hline & & $\begin{array}{l}\text { projectDeliverables is a non-empty } \\
\text { set of the different products } \\
\text { delivered during the system } \\
\text { implementation project (e.g. } \\
\text { hardware, software, documents, etc.) }\end{array}$ & $\begin{array}{l}\text { ProjectDeliverables }=\text { Set(ProjectDeliverable) } \\
\text { ProjectDeliverable }=\text { Domain (hardware, software, data and } \\
\text { documents provided or paid by customer as project } \\
\text { deliverables, etc.) }\end{array}$ \\
\hline & \multirow{3}{*}{$\begin{array}{l}\text { Extended Part } \\
\text { Review Focus }\end{array}$} & Form Text & $\begin{array}{l}\text { The customer shall focus the quality assessment on the } \\
\text { quality Aspects. }\end{array}$ \\
\hline & & Param & Metric \\
\hline & & $\begin{array}{l}\text { qualityAspects is a non-empty set of } \\
\text { the different quality aspects to be } \\
\text { assessed }\end{array}$ & $\begin{array}{l}\text { QualityAspects = Set(QualityAspect) } \\
\text { QualityAspect = Domain (specific development, treatment } \\
\text { of the reported abnormalities, quality procedures, etc.) }\end{array}$ \\
\hline & $\begin{array}{l}\text { Extended Part } \\
\text { Quality Criteria } \\
\text { Agreement }\end{array}$ & Form Text & $\begin{array}{l}\text { The customer shall agree with the supplier the level of } \\
\text { quality expected for the various project deliverables. }\end{array}$ \\
\hline \multirow{15}{*}{$\begin{array}{l}\text { Requirement Form } \\
\text { Quality Standard- } \\
\text { based Assessment }\end{array}$} & Description & \multicolumn{2}{|c|}{$\begin{array}{l}\text { This form expresses the need of setting the customer right for performing quality assessment of the } \\
\text { supplier or of the project assets regarding a quality standard. }\end{array}$} \\
\hline & Constraints & \multicolumn{2}{|c|}{$\begin{array}{l}\text { Fixed part application: }(1) \\
\text { Extended parts application: } \\
\text { Process Quality Assessment }(0 . .1) \\
\text { Deliverables Quality Assessment (*) } \\
\text { Quality Criteria Establishment }(0 . .1) \\
\text { Quality Criteria Agreement (0..1) } \\
\text { Parameter values constraints: } \\
\quad \text { projectDeliverables, qualityStandard DisjointValues (Deliverables Quality Assessment) } \\
\end{array}$} \\
\hline & Fixed Part & Form Text & $\begin{array}{l}\text { If the customer considers it necessary, during the system } \\
\text { implementation project, s/he shall be allowed to assess the } \\
\text { quality of the process or project deliverables taking into } \\
\text { account a quality standard. }\end{array}$ \\
\hline & \multirow{3}{*}{$\begin{array}{l}\text { Extended Part } \\
\text { Process Quality } \\
\text { Assessment }\end{array}$} & Form Text & $\begin{array}{l}\text { The quality of the process shall be assessed taking into } \\
\text { account the qualityStandard quality Standard. }\end{array}$ \\
\hline & & Param & Metric \\
\hline & & $\begin{array}{l}\text { qualityStandard represents the } \\
\text { identifier of the quality standard that } \\
\text { shall be used to assess the quality }\end{array}$ & $\begin{array}{l}\text { QualityStandard = Domain (IEEE830, IEEE829, IEEE1016, } \\
\text { ISO/IEC9126, ISO/IEC 15504-5, etc.) }\end{array}$ \\
\hline & \multirow{4}{*}{$\begin{array}{c}\text { Extended Part } \\
\text { Deliverables Quality } \\
\text { Assessment }\end{array}$} & Form Text & $\begin{array}{l}\text { The quality of the projectDeliverables shall be assessed } \\
\text { taking into account the qualityStandard quality Standard. }\end{array}$ \\
\hline & & Param & Metric \\
\hline & & projectDeliverables as above & ProjectDeliverables as above \\
\hline & & qualityStandard as above & QualityStandard as above \\
\hline & $\begin{array}{l}\text { Extended Part } \\
\text { Quality Criteria } \\
\text { Agreement }\end{array}$ & Form Text & $\begin{array}{l}\text { The customer shall agree with the supplier on the level of } \\
\text { quality expected for the project deliverables. }\end{array}$ \\
\hline & \multirow{4}{*}{$\begin{array}{l}\text { Extended Part } \\
\text { Quality Criteria } \\
\text { Establishment }\end{array}$} & Form Text & $\begin{array}{l}\text { The customer shall establish the subset quality standard } \\
\text { criteria to be applied timePreposition date. }\end{array}$ \\
\hline & & Param & Metric \\
\hline & & $\begin{array}{l}\text { timePreposition represents the } \\
\text { relationship with respect to a date }\end{array}$ & timePreposition = Domain (on, before, after, at, by ....) \\
\hline & & $\begin{array}{l}\text { date is a time point representing the } \\
\text { date in which the quality standard } \\
\text { criteria shall be established }\end{array}$ & Date $=$ TimePoint \\
\hline
\end{tabular}

